\title{
Digital consumer culture and Digital acculturation
}

\begin{abstract}
The advent of digital technology has significantly transformed human lives and added new dimensions to our consumption behaviours. Responding to these constant changes in socio-cultural dynamics, this commentary defines and theorises digital consumer culture and explains how digital consumer culture facilitates digital acculturation. We pioneer a conceptual framework that explains the reciprocal, iterative and dynamic inter-relationships between digital consumer culture and digital acculturation and spells out the three inherence characteristics of digital consumer culture. These include consumer empowerment, reciprocity between online and offline worlds and decompartmentalisation of identities; together they make digital consumer culture unique. Finally, by identifying and discussing three outcomes of digital acculturation: digital integration, digital separation and digital deprivation, we make further contribution to theories, with the view of generating debates in studying acculturation in the digital age.
\end{abstract}

Keywords: Social media, acculturation, digital consumer culture, digital acculturation

\section{Introduction}

Human interaction with global and local communities found a new mode with the advent of Web 2.0 technology and the subsequent uptake of social media (Hajli, 2014). The simultaneous diffusion of mobile technology pervading across the social strata (Rahman, et al. 2019; Dey et a. 2016; Aricat, 2015) has coincided with and complemented this development and, together, they have expanded the boundaries of intra and inter-community interactions and recreated symbiotic dynamics between the online and offline world. The convenience and connectedness provided by social media, mobile technology and other forms of digital technologies and applications promote assimilation, integration or acculturation beyond the users' 'own community' (Yen and Dey, 2019). The definition of community is also becoming increasingly fluid as people transiently demonstrate multiple identities (Kizgin, et al. 2017; Yu et al. 2018; Dey et al., 2017).

It is argued that postmodern consumers in a neoliberal age often demonstrate paradoxical behaviour (Firat and Venkatesh, 1995) and their use of digital technologies perpetuates further engagement with the groups that share their own views and beliefs, regardless of geographical distance (Phillips, 2008). However, scholars also argue that in recent time 
especially after 2007-9 financial crisis the Western liberal values and social norms that espouse inclusivity, diversity and economic liberalisation have received strong challenges from what is considered as post liberal way of social and political doctrine that encourages populist views, contests elitism (Pabst, 2016). The surge of extreme right and significant popularity of radical left political views across the West provide a plausible explanation for this trend. This phenomenon coincides with if not is co-constructed with the social media and digital technology led lifestyle that breaks barriers and enables people to have their voice and views heard (Ali et al. 2019; Sorour and Dey, 2014), does not matter if it lacks political correctness and/or contravenes liberal ethos (Grover et al. 2019; Jamal et al. 2019). Social media at the same time divides and segregates people (Yen and Dey, 2019), although popular norms suggest that it converges consumers and their cultures across the world. Often for instance, the diffusion of messages on social media is not content neutral and the collective generation of content reflects and reinforces existing group memberships in reality (Lipizzi et al., 2016; Cappellini and Yen, 2013).

Simultaneously, due to globalisation (Neal et al., 2013; Akaka et al., 2013), environmental disasters (Reuveny, 2007) and wars (Ruiz and Vergas-Silva, 2012), the migration of human race continues and the world is experiencing heterogenous and diverse composition of societies. As such, research into consumer acculturation towards Western multicultural societies (Askegaard et al., 2005; Peñaloza, 1994) and global consumer culture (Cleveland and Laroche, 2013) has gained currency in management scholarship. Despite the advancement of digital technologies and borderless boundaries, the role of social media and other digital applications in consumer acculturation has been understudied, leaving inadequate conceptual scaffolding and empirical application of acculturation in the digital world. Social media and digital technology enable ethnic communities to express their identity (Dey et al. 2018a), engage with political activities (Kizgin, et al. 2019) and learn about regional and international cultural attributes (Fujita et al. 2019). Despite, growing body of research in individual and communal interaction and engagement through digital media, the acculturation through and within digital platforms has not been properly conceptualised and/or defined. We term this phenomenon as digital acculturation and explore its various aspects in this paper. Hence, This commentary aims to address some notable dearth in scholarly works by introducing and linking digital consumer culture and digital acculturation.

It needs to be mentioned that despite significant research on consumers' interaction with digital media (Ma et al. 2017; Forbush and Foucault-Welles, 2016; Kozinet and Cereno, 
2014) and its subsequent influence on their cultural disposition (Dhir et al. 2016; Aricat, 2015; Belk, 2014), the concept of digital consumer culture has not been properly coined or defined. However, digital consumer culture requires much research attention, which can be initiated through proper conceptual underpinning and theoretical positioning of the term, which is missing from the existing body of literature. Acknowledging the dearth of research in acculturation literature that conceptualises the new dynamics of our daily lives resulting from the use of social media and other digital technologies or applications, we seek to introduce and define the concept of digital consumer culture and to discuss consumers' acculturation in the digital world. Specifically, we aim to

1) Conceptually depict digital consumer culture and demonstrate how it differs from consumer culture in general.

2) Discuss digital acculturation and how it fits into the study of digital consumer culture.

The paper has three major conceptual constructs: a) digital consumer culture, b) digital acculturation and c) their interrelationship that defines the scope for future conceptual/theoretical advancement.

\section{Digital consumer culture:}

Consumer culture goes far beyond the consumption of material products as it encapsulates the practices, identities and symbolic meanings embedded within people's daily lives, constituted by the individual and collective perceptions and lived experiences of the consumption. Consumer culture denotes the social arrangement defined by the interrelationship between a community's lived experiences and their material surroundings mediated through marketplace interactions (Arnould and Thompson, 2005). In a neo-liberal and post-modern world, consumption practices, and their symbolic presence in human lives, are central to consumer culture. Post liberalism further enables consumers to harbour and purport extremist and unconventional views and lifestyle. Often eccentric and alternative views of minorities gather momentum by diffusing through social media. While consumer culture literature over the last decade has examined consumer interaction with brands, companies, market institutions and market dynamics, it has fallen short of capturing the evolution of the digital world and the consequential implications on consumers' daily lives. To address this knowledge gap, we introduce the notion of digital consumer culture, through which we refer to the shared sets of consumption behaviour that directly or indirectly emanate from people's interactions with digital technologies, such as the Internet, social 
media, mobile devices and applications. In doing so, we take the consumer culture literature beyond its current remit (of marketing literature) by integrating it with technology and information systems scholarship. An emerging digital culture is expressed, and such a culture thus has implications on a shared social level - both online and offline (Deuze, 2006).

Consumer interaction with the material world has evolved with the advent of digital technology. Their purchase pattern, use of products and overall lived experience have undergone change. For example, to satisfy the need to store and share information, we have moved from floppy disk to CD drive to USB sticks to Cloud storage. Many of us have also changed our shopping behaviour, moving from the physical 'market' to online trading sites. Overall, consumers' online and offline lives are inextricably interwoven nowadays and they have more complex orientation with, and assessment of, their social and business environments and institutions. As such, digital consumer culture merits separate attention and ought to emerge as a distinct research stream in its own right.

However, digital consumer culture is not only confined within people's interactions and behaviour online, as often the online and offline boundaries are blurred and overlapped. In fact, people have stopped differentiating the online from the offline, but have embraced the lived convenience brought by technology as an all-encompassing experience. For instance, people might purchase a product from an online retailer but their actual consumption experience in the offline world can have a bearing on their post-purchase evaluations of their online shopping behaviour. Likewise, villagers in remote parts of developing countries adopt mobile financial services to gather funds to improve their lived experience of the offline world (Dey et al. 2018b; Rahman et al. 2019). Therefore, digital consumer culture is constituted through the iterative and reciprocal interactions between the online and the offline world, through individual, social and business behaviours and practices. To shed new light on future research into digital consumer culture as a distinct research stream, we highlight the tripartite characteristics of digital consumer culture:

1) Digital consumer empowerment:

In these times of online communities with the use of Web 2.0, the postmodern view of the consumers is becoming a reality. As information systems research has pointed out, it has been argued that the dramatically decreasing costs of information technology is changing the economics of decision making, shifting power down the hierarchy and leading to decentralised organisations (Malone, 1999), giving rise to a new era of peer production. (Von 
Hippel, 2005). The internet is transforming "information scarcity' into 'information democracy' (Sawhney and Kotler, 2001) or 'transparency' (Deshpande, 2002). Because consumer empowerment derives substantially from the knowledge that consumers appropriate from the internet and from other sources, the extent of empowerment will depend on their ability to discern potentially useful information for evaluating competing products on offer and to satisfy their needs and wants with minimal time, effort and energy. Consumers are much empowered through their engagement with digital technology, particularly the Internet and social media (Cappellini and Yen, 2013). Consumers' interactions amongst and beyond their national, ethnic and geographical boundaries offer them greater power. The freedom to interact, approach, support, oppose and criticise social, cultural and business institutions on social media empowers consumers with a proactive voice. Celebrities and politicians are openly criticised for their wrongdoings on social media. Blog posts and YouTube videos have made it possible for individuals to become micro-celebrities ${ }^{1}$, with large follower groups and the potential to influence public opinions (Kozinets and Cereno, 2014). Bloggers and micro-celebrities have even taken to the streets to lead socio-political movements, as can be seen in the case of Tahrir Square in Egypt and the Shahbag movement in Bangladesh (Sorour and Dey, 2014). Systematically, we can say that postmodern consumers living in a digital culture era are more empowered through a number of factors such as expecting quality and compliance with what the market has to offer, extracting value propositions and engagement. We identify these characteristics as the three E's of consumer empowerment that define a significant part of digital consumer culture. The potential fast pace growth of the Internet increases the demand and supply as well as the quality of search engines and social media platforms available to digital consumers thereby creating synergies between networks across the globe and enhancing market competition which increases with increasing supply that directly influences the value propositions from which post-industrial consumers can choose. This rising trend in digital engagement and high degree of personalised expectations has contributed towards digital consumer culture by providing consumers with the autonomy to have their say beyond the control of traditional mass media. This is in line with Deuze's (2006) concept of participation as a core element of the currently emerging digital culture with its roots in "DIY" (do it yourself) culture, with people increasingly claiming the right to be heard rather than be spoken to which incorporates the 
notions of mutuality, solidarity, interactivity and the freedom to choose affiliations (Hartley, 1999).

2) Promoting reciprocity between the online and offline world:

Earlier works, such as that by Boellstorff (2008), showed that people tend to adopt 'the second life' in the online world and such a parallel existence might not always reflect real life. However, through the advancement of digital technology, we challenge this assumption by arguing that people will not always have parallel lives in online and offline worlds because re-embodiment, sharing and co-construction are the three salient features of human interaction with online media (Belk, 2014). If a second life is available online, technology advancement has facilitated and contributed to the constant overlapping of the two. Facebook statuses, check-ins, posts, selfies and the availability of virtual augmented reality increasingly reflect, keep track of and connect an individual consumer's offline self to their online presence. Often consumer culture in the offline world is shared, reinforced, reified and endorsed through online expressions; for instance, selfie posts are employed to tangibilise and endorse one's self-imposed identity on social media. Online fads and fashions influence people's offline lives and consumption practices. For example, the 'ice bucket challenge' was taken up by many around the world to show and tell their support of a charitable act, both online and offline. This digital culture has emergent properties with roots in both online and offline phenomena, with links to trends and developments predating the world wide web, yet having an immediate impact and particularly changing the ways in which we use and give meaning to living in an increasingly interconnected digital environment. Hence, the gap between the actual life and digitally enabled second life is decreasing due to the reciprocal influence between the two.

3) Decompartmentalisation of consumer identities:

Self concept has been an important topic of study in consumer behaviour. Over the years, the conceptualization of the self as a single, unified, and coherent entity has changed and is now recognized to be multidimensional, divided and complex issue. Bahl and Milne's (2010) study on the dialogical exploration of consumption experiences explains how consumers deal with differences in their consumption preferences across their selves by using the dialogical self-theory by Hermans and Kempen's (1993) framework which recognizes the self at three levels- the metaself, the I-positions, and the me's. They discovered six types of dialogical relationships between selves at I-positions, which were compassion, compartmentalisation, 
negotiation, coalition, opposition and domination. We apply this taxonomy to build conceptualise expression of identity in the digital world. The compartmentalisation strategy can be linked to the rising digital consumer culture, where compartmentalisation can facilitate the pursuit of different constellations of consumption behaviours constituting different Ipositions, such as in the case of social media usage, that often leads to boundary blurring between our private, social and occupational lives. The object/activity is an important part of some I-position as the participant continues to engage in that behaviour as long as it remains in the domain of that particular I-position. However, as social media posts and interactions are often public and shared amongst friends, family members, work colleagues and even acquaintances, the ability to move easily between different I-positions to cater to self desire wants and needs can be a problematic issues as there is an increasing difficulty for consumers in expressing their identities differently to each specific group. This tension may also happen amongst celebrities. During the Brexit debate some of the Twitter posts of famous BBC and BT Sport broadcaster and former England football player Gary Lineker created controversies as he vehemently supported a second referendum and criticised Brexit policies through his official Twitter page. Although the opportunity for closed group discussions in social media, and the selective privacy setting, can help individuals to maintain their compartmentalised identities, it is somehow difficult to juggle several different, conflicting or competing identities at the same time. For example, some professionals might use work-based social media to share their occupational achievements, promote their businesses and interact with their colleagues within their organisation and across the sector; however, they might be using other social media at the same time to express their interests, choice of celebrities and/or support for political alignment. Whilst this identity compartmentalisation strategy might have worked a few years ago, the powerful search engines available nowadays often mean that their digital footprint can be tracked and recorded more easily, linking to their future reputation (O'Keeffe and Clarke-Pearson, 2011). For example, US comedian and actor Kevin Hart has stepped down from hosting 2019 Oscars amid a tweet row which emerged from decades ago (bbc.co.uk, 2018). 


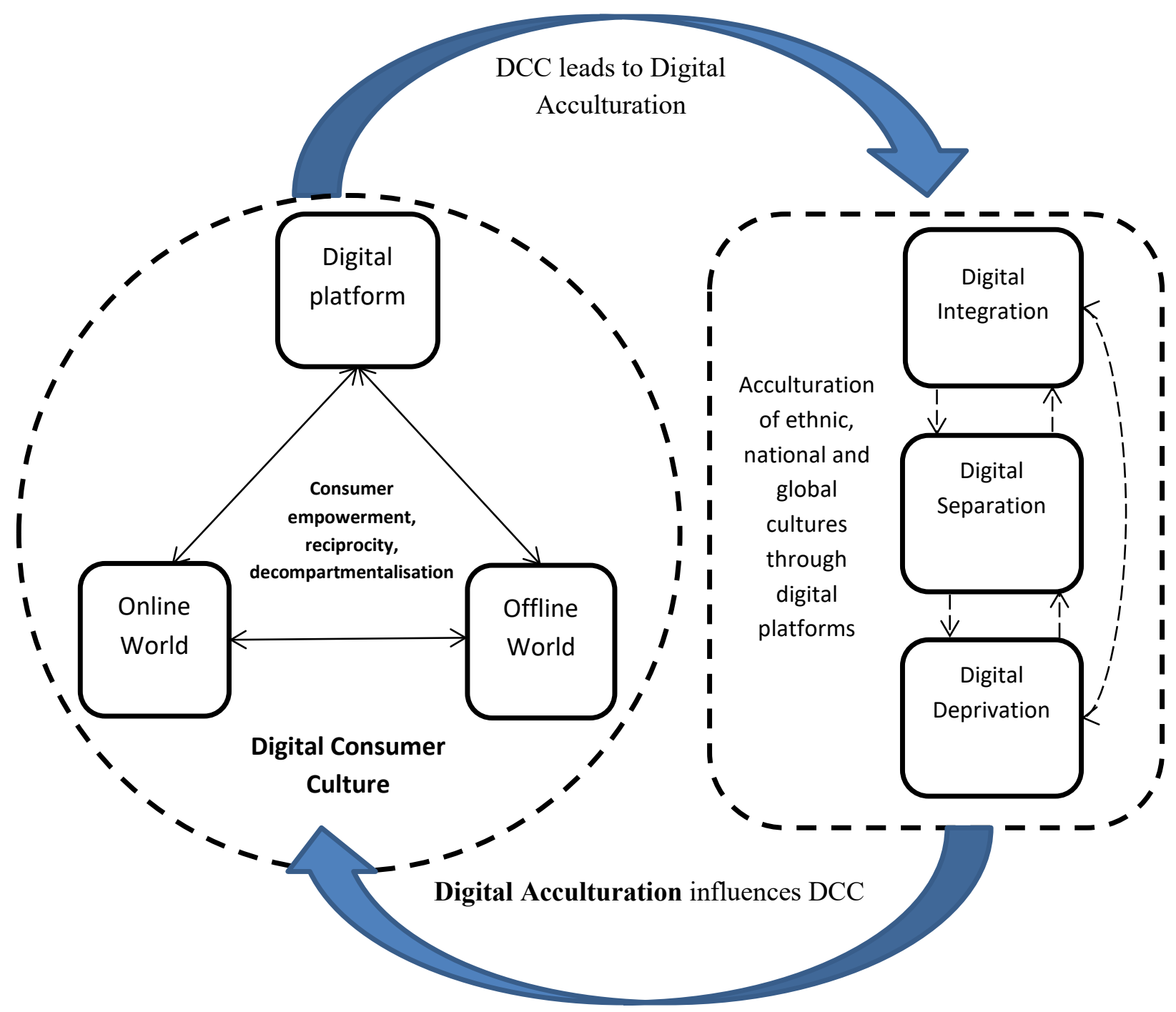

Figure 1 Inter-relationship between digital consumer culture and digital acculturation

Figure1 explicates the conceptual model for digital consumer culture and how it relates to digital acculturation. The circle on the left-hand side of the diagram depicts the dynamics of digital consumer culture emanating from the interplay between the three key elements - the offline world, the online world and digital platforms. The constant and iterative interactions between these three entities determine the nature and outcome of consumers' lifestyles, their interactions with their socio-economic surroundings and their expression and formulation of consumer identities. These dynamic interrelationships co-create digital consumer culture, perpetuating its tripartite characteristics: consumer empowerment, reciprocity between the online and offline world and the decompartmentalisation of consumer identities. As such, the circle on the left-hand side denotes the very notion that the offline world and online world, 
through their inextricable and interwoven relationship, enshrined within various digital platforms, such as social media and smartphone based applications, give rise to digital consumer culture.

\section{Digital acculturation}

Whilst the tripartite characteristics of digital consumer culture collectively explain how it develops from consumer culture, they also highlight a new pattern of social interactions between in-group and out-group members beyond traditional classification of social categories, such as class, locality and ethnicity. Instead, digital consumer culture facilitates the emergence of different social groups based on other common grounds, for example, common interests, shared habits, choice of celebrities, support of political stances and consumption practices. Belk (2013) highlighted that in a digital world, the self is now extended into avatars, broadly construed, with which consumers identify strongly and which can affect offline behaviour and sense of self. The aggregate self can no longer be conceived from only a personal perspective and is not only jointly constructed but shared, that is a joint possession with others. Consumers are now beginning to have traces of consumption that act as cues to a personal and aggregate sense of past, which are not only encoded in private possessions but are now more likely to turn to digitized and shared mementos online. These memory cues are likely to be commented on or responded to by others in a much more active co-construction of collective sense of past. All of these phenomena are dramatically new and they suggest that only studying extended self offline is missing a large part of the influences on the consumers' self concepts and others' activities in creating them.

Acculturation literature focuses on how consumers acculturate to others of different ethnic cultures or nationalities (Oswald, 1999; Peñaloza, 1994; Berry, 1980). Earlier scholarship (Berry, 1980) in this field suggests acculturation is a mono-dimensional process. Subsequently, post-assimilationist literature (Oswald, 1999; Peñaloza, 1994) consider acculturation as a bi-dimensional process, as members of ethnic communities can at the same adopt host community's culture and retain their own. Acculturation strategies are outcome of acculturation process and influence of certain drivers. Whilst the presence of these drivers and processes are not context independent, the nature and outcome of acculturations strategies are also likely to have varied forms as suggested in post 2000 acculturation literature (Dey et al. 2017; Lindridge, 2009; Askegaard et al., 2005; Jamal, 2003). Furthermore, acculturation does not always take place between ethnic culture and host culture, it can also happen between local 
and global consumer culture (Cleveland et al.2007). In multicultural societies acculturation can have more complex form, as people interact with and adopt cultural attributes of different ethnic and religious groups (Dey et al. 2019). As such, the acculturation scholarship has evolved over the years and taken into account various modes, methods and strategies of individual and communal adoption of cultures. As mentioned in the introductory section of this commentary, the role of social media makes acculturation processes and outcomes even more complex. Drawing on Dey et al. (2019) multi-dimensional perspective to acculturation, thus far provides conceptual impetus for future research involving acculturation and digital platforms.

As such, we revisit the notion of acculturation in digital consumer culture, as a debate on how we acculturate to "others" beyond ethnicity or nationality can potentially advance and enrich our current understanding of acculturation. The role of social media has been largely ignored when it comes to acculturation outcomes and consumption choices, hence why it is extremely important to acknowledge that digital media is an effective means of communicating, promoting and supporting the activities and interactions amongst peers, consumers and organisations that transcend the boundaries of time and space (Erkan and Evans, 2016; Jin 2012; Sharma et al. 2013; Tang et al. 2015). In this paper, we define digital acculturation as the process of expressing and managing individuals' identities and practices within the social and cultural boundaries created and characterised by the dynamic interrelationships between, and amongst, online and offline worlds. Therefore, the concept captures the interactions, perceptions, paradoxes and intricacies pertaining to consumers' exposure to digital consumer culture.

Digital consumer culture leads to digital acculturation, as it creates/recreates consumers' interactions and identity formation in the digital age. Digital acculturation has three major outcomes: digital integration, digital separation and digital deprivation. Unlike in traditional acculturation literature, e.g. Berry (2008), the concept of assimilation is ignored, as we feel that individuals cannot completely immerse themselves in a different culture or culture group, by dissociating themselves entirely form their original culture groups as argued by Dey et.al (2017). Furthermore, while consumers are more empowered by digital consumer culture, they are more likely to maintain their identity fluidity and to enjoy the freedom to sample, interact and experience various communities, facilitated by digital consumer culture. 
Digital integration refers to the state of acculturation when individuals and communities adopt certain cultural attributes of a different cultural group, through their dynamic interaction with the online and offline world, without completely discarding their original cultural attributes. For instance, people interact and engage with various groups in social media to exchange ideas and practices, but neither have they become completely immersed in the new cultures, nor have they given up their original cultures or previous practices. Instead, a comfortable pick-and-choose attitude is adopted when negotiating between and/or amongst different communities. Therefore, the acculturation scholarship ought to appraise the importance of social media to the formation and/or deconstruction of communal identities. When minority consumers frequently interact with other cultural groups via social media, they can construct, reinforce and/or deconstruct/recreate multiple identities in an online context. The notion does not contradict rather complements existing acculturation literature that argues that ethnicity in a contemporary marketplace is like a bricolage, where a consumer builds his or her self-identity from elements taken from diverse cultural representations and practices (Lindridge et al, 2015; Jamal, 2003)

However, the convenience and connectedness provided by social media do not always promote integration or acculturation beyond the users' 'own community'. Thus, digital separation refers to the state whereby digital platforms are used only for interacting and strengthening the bonds amongst those within the in-group. Here, consumers have the scope and opportunities, but lack willingness to engage with members of other communities. As evidenced by the recent United States (US) presidential election, by creating, reinforcing and perpetuating interactions within the in-groups, rather than connecting the out-groups, social media leads to increasing social polarisation, failing to facilitate further acculturation between groups. Unlike in the offline world, where people are often forced to interact with members of other nationalities, ethnicities, faith groups and ideologies due to their unavoidable physical presence (Dey et al., 2017), in the online world consumers can choose who to follow and with whom to interact, thanks to the empowerment offered by digital consumer culture, separating them from the wider world and isolating their views and voices.

Digital deprivation is the state where consumers are unable to access online communities and cultures for various reasons, such as resource constraints, lack of skills or expertise and political or government censorship. In this way, we regard farmers in African villages as being digitally deprived for their lack of access to the Internet due to absence of resources and skills. However, whilst the Chinese government restricts its citizen's Internet access of 
search engines, such as Google, websites, such as Wikipedia, and social media, such as Facebook, for political reasons, we consider that, despite many Chinese consumers being well educated and having the skills and resources to navigate freely in digital consumer culture, they are also digitally deprived due to the government's political restriction. Therefore, digital deprivation is different from digital separation, as digitally deprived consumers might have the willingness to connect, but their access to the digital consumer culture is somehow limited.

Digital integration, separation and deprivation are, however, not static states. Consumers can move from one state to another, as shown through the arrows in the diagram. With the advent of new social media platforms (such as Snapchat and Instagram) and the constant development of new interest groups and membership, consumers can be regarded as digitally integrated at one point but then digitally separated at the next, depending on context. Furthermore, changes in government regulations and consumers' physical movement might also affect consumers' access to digital consumer culture and their group memberships; thus, we argue that consumers' acculturation outcomes in the digital world are hyper fluid and that there is a constant movement between being digitally integrated, digitally separated and digitally deprived.

Although digital acculturation is derived from digital consumer culture, it also has a recursive influence on digital consumer culture, as we have illustrated in Figure 1. Through digital acculturation, consumers' interactions with online and offline worlds and various digital platforms are defined, changed and/or reinforced. This is a dynamic and spiralling process that is constantly changing, reflecting and shaping current and future innovations and social changes.

\section{Theoretical contribution and scopes for future research:}

This paper advances the previous understanding of acculturation and social media in four ways. Firstly, by defining and introducing the notion of digital consumer culture, we pave the way to a new area where future academic research is required. Secondly, this paper provides the conceptual scaffolding for digital acculturation by explicating the interrelationship between various factors and agents that shape digital consumer culture and influence digital acculturation. Thirdly, the paper also expands on the studies of acculturation by identifying three acculturation outcomes in digital consumer culture - digital integration, digital separation and digital deprivation. Finally, the paper provides more effective taxonomy to 
identify, define and analyse various consumer segments in the digital age and offers conceptual underpinning for digital technologies' roles in formulating current and future social dynamics.

This paper coins the concept and paves the way to further conceptual and empirical scholarly works on both digital consumer culture and digital acculturation. The two concepts offer motivation for both positivist and interpretivist enquiries. The current measurement scales used for acculturation outcomes, such as integration and separation, need to be revisited and new items for operationalising the constructs in our model need to be developed. On the other hand, future interpretivist research is advised to investigate the interrelationships and to advance the conceptual underpinning. 


\section{References:}

Ahuvia, A. (2005). Beyond the Extended Self: Loved Objects and Consumers' Identity Narratives. Journal of Consumer Research, 32(1),171-184. https://www-jstororg.ezproxy.brunel.ac.uk/stable/10.1086/429607

Akaka, M. A., Schau, H. J., \& Vargo, S. L. (2013). The Co-Creation of Value-In-CulturalContext. Consumer Culture Theory, UK: Emerald Group Publishing Limited, 265-284. 10.1108/S0885-2111(2013)0000015018

Ali, M., Azab, N., Sorour, K. \& Dora, M. (2019). Integration v. polarisation among social media users: Perspectives through social capital theory on the recent Egyptian political landscape. Technological Forecasting and Social Change, 145,461-473. 10.1016/j.techfore.2019.01.001

Askegaard,S., Arnould, E. J. \& Kjeldgaard, D (2005). Postassimilationist Ethnic Consumer Research: Qualifications and Extensions. Journal of Consumer Research, 32(1),160-170. $\underline{10.1086 / 426625}$

Aricat, R.G. (2015). Is (the study of) mobile phones old wine in a new bottle? A problematic on communication-based acculturation research. Information Technology and People, 28(4), 806-824. 10.1108/ITP-09-2014-0223

Arnould, E.J. \& Thompson, C. (2005). Consumer culture theory: twenty years of research. Journal of Consumer Research, 31(4),868-882. https://www-jstororg.ezproxy.brunel.ac.uk/stable/10.1086/426626

Bahl, S. \& Milne, G. (2010). Talking to Ourselves: A Dialogical Exploration of Consumption Experiences. Journal of Consumer Research, 37(1), 176-195. 10.1086/650000

Bbc.co.uk. Hart quits as Oscars host amid tweets row. (2018). https://www.bbc.co.uk/news/entertainment-arts-46479017.Accessed 25 Mar. 2019.

Belk, R. W. (2014). Digital consumption and the extended self. Journal of Marketing Management, 30(11-12), 1101-1118. 10.1080/0267257X.2014.939217 
Berry, J. W. (1980). Acculturation as varieties of adaptation in acculturation: theory, models and findings. In Padilla, M. A. (Eds.), Boulder Colorado: Westview Press, pp. 9-25.

Berry, J.W. (2008). Globalisation and acculturation. International Journal of Intercultural Relations, 32(4), 328-336. 10.1016/j.ijintrel.2008.04.001

Boellstorff, T. (2008), Coming of Age in Second Life: An Anthropologist Explores the Virtually Human, Princeton, NJ, Princeton University Press.

Cappellini, B. \& Yen, D. (2013). Little Emperors in the UK: acculturation and food over time. Journal of Business Research, 66(8), 968-974. 10.1016/j.jbusres.2011.12.019

Deshpande, R. (2002). Performance companies. International Journal of Medical Marketing, 2(3), 225-32.

Deuze, M. (2006). Participation, Remediation, Bricolage: Considering Principal Components of a Digital Culture. The Information Society, 22(2), 63-75. 10.1080/01972240600567170

Dey, BL., Alwi, S., Yamoah, F., Agyepong, S., Kizgin, H. \& Sarma, M. (2019). Towards a Framework for understanding Ethnic Consumers Acculturation Strategies in a Multicultural Environment: A Food Consumption Perspective. International Marketing Review, 36(5), 771 - 804. 10.1108/IMR-03-2018-0103

Dey, BL., Balmer, JMT., Pandit, A. \& Saren, M. (2018a). Selfie appropriation by young British South Asian adults: reifying, endorsing and reinforcing dual cultural identity in social media. Information Technology and People, 31(2),482 - 506. 10.1108/ITP-08-2016-0178

Dey, BL., Babu, MM., Rahman, M., Dora, M. \& Mishra, N. (2018b). Technology upgrading through co-creation of value in developing societies: Analysis of the mobile telephone industry in Bangladesh. Technological Forecasting and Social Change, 145, 413 - 425. $\underline{10.1016 / \text { j.techfore.2018.05.011 }}$ 
Dey, B. L., Balmer, J.M.T., Pandit, A., Saren, M. \& Binsardi, B. (2017). A Quadripartite Approach to Analysing Young British South Asian Adults' Dual Cultural Identity. Journal of Marketing Management, 33 (9/10), 789-816. 10.1080/0267257X.2017.1324896

Dey, BL., Pandit, A., Saren, M., Bhowmick, S. \& Woodruffe-Burton, H. (2016). Co-creation of value at the bottom of the pyramid: Analysing Bangladeshi farmers' use of mobile telephony. Journal of Retailing and Consumer Services, 29 (2).40 - 48. $\underline{10.1016 / j . j r e t c o n s e r .2015 .10 .009}$

Dhir, A., Pallesen, S., Torsheim, T. \& Andreassen, C. S. (2016). Do age and gender differences exist in selfie-related behaviours? Computers in Human Behavior, 63, pp. 549555. 10.1016/j.chb.2016.05.053

Erkan, I., \& Evans, C. (2016). The influence of eWOM in social media on consumers' purchase intentions: An extended approach to information adoption. Computers in Human Behavior, 61, 47-55. 10.1016/j.chb.2016.03.003

Firat, A. F. \& Venkatesh, A. (1995). Liberatory postmodernism and reenchantment of consumption. Journal of Consumer Research, 22 (3), 239-267. 10.1086/209448

Forbush, E. \& Foucault-Welles, B. (2016). Social media use and adaptation among Chinese students beginning to study in the United States. International Journal of Intercultural Relations, 50, 1-12. 10.1016/j.ijintrel.2015.10.007

Grover, P., Kar, A., Dwivedi, Y. \& Janssen, M. (2019). Polarization and acculturation in US Election 2016 outcomes - Can twitter analytics predict changes in voting preferences. Technological Forecasting and Social Change, 145, 438-460. 10.1016/i.techfore.2018.09.009

Hajli, M.N. (2014). The role of social support on relationship quality and social commerce. Technological Forecasting and Social Change, 87, 17-27. 10.1016/j.techfore.2014.05.012

Hartley, J. (1999). Uses of television. London: Routledge.

Hermans, Hubert J. M. \& Harry J. G. Kempen (1993). The Dialogical Self: Meaning as Movement, New York: Academic Press. 
Jamal, A., Kizgin, H., Rana, N.P., Laroche, M. \& Dwivedi, Y.K. (2019). Impact of acculturation, online participation and involvement on voting intentions. Government Information Quarterly, 36(3), 510-519. https://doi.org/10.1016/j.giq.2019.04.001

Jamal, A. (2003). Marketing in a Multicultural World: The Interplay of Marketing, Ethnicity and Consumption. European Journal of Marketing, 37(11/12), 1599-1622. $\underline{10.1108 / 03090560310495375}$

Janssens, M. \& Zanoni, P. (2014), Alternative Diversity Management: Organizational Practices Fostering Ethnic Equality at Work. Scandinavian Journal of Management 30(3), 317-331. 10.1016/j.scaman.2013.12.006

Jin, S. A. (2012). The potential of social media for luxury brand management. Marketing Intelligence \& Planning, 30(7), 687-699. 10.1108/02634501211273805

Kizgin, H., Dey, B., Dwivedi, Y.D., Hughes, L., Jamal, A., Jones, P., Kronemann, B., Laroche, M., Penaloza, L., Richard, M.O., Rana, N.P., Romer, R., Tamilmani, K. \& Williams, D. (2019). The impact of social media on consumer acculturation: Current challenges, opportunities, and an agenda for research and practice. International Journal of Information Management. doi.org/10.1016/j.ijinfomgt.2019.10.011

Kizgin, H., Jamal, A., Dey, BL. \& Rana, N. (2017). The impact of Social Media on Consumers' Acculturation and Purchase Intentions. Information Systems Frontiers, 20 (3),503 - 514. 10.1007/s10796-017-9817-4

Kizgin, H, Jamal, A., Rana, N., Dwivedi, Y. \& Weerakkody, V. (2019). The impact of social networking sites on socialization and political engagement: Role of acculturation. Technological Forecasting and Social Change, 145, 503-512. 10.1016/i.techfore.2018.09.010

Kozinets, R. \& Cereno S. (2014). Between the suit and the selfie: executives' lesson on the social micro-celebrity", GFK Market Intelligence Review, 6(2), 21. https://doi.org/10.2478/gfkmir-2014-0093

Lindridge, A. M. (2009). Acculturation, religion and consumption in normative political ideology. Advances in Consumer Research, 36(1), pp. 16-19. http://www.acrwebsite.org/volumes/14382/volumes/v36/NA-36 
Lindridge, A., Henderson, G. R., \& Ekpo, A. E. (2015). Virtual ethnicity, the internet, and well-being. Marketing Theory, 15(2), 279-285. 10.1177/1470593114553328

Lipizzi, C., Landoli, L. \& Marquez, JEM. (2016). Combining structure, content and meaning in online social networks: The analysis of public's early reaction in social media to newly launched movies. Technological Forecasting and Social Change. 109, 35-49. 10.1016/j.techfore.2016.05.013

Ma, J.W., Yang. Y. \& Wilson, J.A.J. (2017). Window to the ideal self: A study of UK Twitter and Chinese Sina Weibo selfie-takers and the implications for marketers. Journal of Business Research, 74, 139-142. 10.1016/j.jbusres.2016.10.025

Malone, T.W. (1999). Is "empowerment" just a fad? Control, decision-making, and information technology. BT Technology Journal, 17 (4), 141-144. https://doi.org/10.1023/A:1009663512936

Neal, S., Bennett, K., Cochrane, A. \& Mohan, G. (2013). Living Multiculture: Understanding the New Spatial and Social Relations of Ethnicity and Multiculture in England. Environment and Planning C: Government and Policy, 31(2), 308-323. 10.1068/c11263r

O'Keeffe, G.S. \& Clarke-Pearson, K. (2011). The impact of social media on children, adolescents, and families. Pediatrics, 127(4), 800-804. https://doi.org/10.1542/peds.20110054

Oswald, L. R. (1999). Culture swapping: Consumption and the ethnogenesis of Middle-Class Haitian immigrants. Journal of Consumer Research, 25(4), 303-18. 10.1086/209541

Peñaloza, L. (1994). Atravesando Fronteras/Border Crossings: A Critical Ethnographic Exploration of the Consumer Acculturation of Mexican Immigrants. Journal of Consumer Research, 21(1), 32-54. 10.1086/209381

Phillips, F. (2008). Change in socio-technical systems: Researching the multis, the biggers and the more connecteds. Technological Forecasting and Social Change, 75, 3, 1-20. $\underline{10.1016 / j . t e c h f o r e .2008 .03 .005}$

Rahman, M., Bose, S., Babu, MM., Dey, BL., Roy, SK. \& Ben, B. (2019). Value CoCreation as a Dialectical Process: Study in Bangladesh. Information Systems Frontiers, 21(3), 527-545. 10.1007/s10796-019-09902-4 
Riefler, P., Diamantopoulos, A. \& Siguaw, J. A. (2012). Cosmopolitan Consumers as a Target Group for Segmentation. Journal of International Business Studies, 43(3), 285-305. $\underline{10.1057 / j i b s .2011 .51}$

Reuveny, R. (2007). Climate changed-induced migration and violent conflict. Political Geography, 26, 656-673.

Rossiter, J. R. \& Chan, A. M. (1998). Ethnicity in Business and Consumer Behaviour. Journal of Business Research, 42(2), 127-134. 10.1016/S0148-2963(97)00113-6

Ruiz, I. \& Vergas-Silva, C. (2012). The economics of forced migration. The Journal of Development Studies, 49 (6), 772-784. 10.1080/00220388.2013.777707

Sarpong, D \& Maclean, M. (2015). Service Nepotism in the Multi-Ethnic Marketplace: Mentalities and Motivations. International Marketing Review. 32(2), $160-180$. $\underline{\text { 10.1108/IMR-01-2014-0030 }}$

Sawhney, M. \& Kotler, P. (2001). Marketing in the age of information democracy. In Iacobucci, D. (Eds.), Kellogg on Marketing, Wiley, New York, NY (pp. 386-409).

Sharma, G., Qiang, Y., Wenjun, S., \& Qi, L. (2013). Communication in the virtual world: Second life and business opportunities. Information Systems Frontiers, 15(4), 677-694. $\underline{10.1007 / \mathrm{s} 10796-012-9347-\mathrm{z}}$

Sorour, K. \& Dey, BL. (2014). Energising political movements in developing countries: The role of social media. Capital and Class, 38(3), 508 - 515. 10.1177/0309816814550390

Tang, J., Zhang, P., \& Wu, P. (2015). Categorizing consumer behavioral responses and artifact design features: The case of online advertising. Information Systems Frontiers, 17(3), 513-532. 10.1007/s10796-014-9508-3

Yu, Q., Foroudi, P. \& Gupta, S. (2019). Far apart yet close by: Social media and acculturation among international students in the UK. Technological Forecasting and Social Change, 145, 493-502. 10.1016/j.techfore.2018.09.026

von Hippel, E. (2005). Democratizing Innovation. Cambridge, MA: MIT Press. 